\title{
Multi-criteria based algorithm for scheduling divisible load
}

\begin{abstract}
Divisible load theory has become a popular area of research during the past two decades. Based on divisible load theory the computations and communications can be divided into some arbitrarily independent parts and each part can be processed independently by a processor. Existing divisible load scheduling algorithms do not consider any priority for allocating fraction of load. In some situation the fractions of load must be allocated based on some priorities. In this paper we propose a multi criteria divisible load scheduling algorithm. The proposed model considers several criteria with different priorities for allocating fractions of load to processors. Experimental result indicates the proposed algorithm can handle the priority of processors.
\end{abstract}

Keyword: Divisible load scheduling; Priority; Multi criteria; AHP 